Canadian

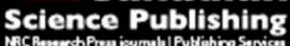

Applied Physiology, Nutrition, and Metabolism Physiologie appliquée, nutrition et métabolisme

\title{
Improving patient's home cooking - A case series of participation in a remote culinary coaching program
}

\begin{tabular}{|r|l|}
\hline Journal: & Applied Physiology, Nutrition, and Metabolism \\
\hline Manuscript ID & apnm-2017-0053.R1 \\
\hline Manuscript Type: & Brief communication \\
\hline Date Submitted by the Author: & $15-$ Mar-2017 \\
\hline Complete List of Authors: & $\begin{array}{l}\text { Polak, Rani; Spaulding Rehabilitation Hospital } \\
\text { Pober, David; Joslin Diabetes Center } \\
\text { Budd, Maggi; VA Boston Healthcare System } \\
\text { Silver, Julie; Spaulding Rehabilitation Hospital } \\
\text { Phillips, Edward; VA Boston Healthcare System } \\
\text { Abrahamson, Martin ; Beth Israel Deaconess Medical Center }\end{array}$ \\
\hline Keyword: & $\begin{array}{l}\text { Health coaching, Eating behavior, Lifestyle Medicine, Home cooking, } \\
\text { nutrition < nutrition }\end{array}$ \\
\hline
\end{tabular}




\section{Improving patients' home cooking - A case series of participation in a remote culinary coaching program}

Rani Polak (1), MD, MBA, David M. Pober (2) PhD, Maggi A. Budd, PhD, MPH (3) Julie K Silver (4) Edward M Phillips (5) MD, Martin J Abrahamson (6) MD.

\section{Author Affiliations}

(1) Institute of Lifestyle Medicine, Spaulding Rehabilitation Hospital, Department of Physical Medicine \& Rehabilitation, Harvard Medical School, Boston, MA

(2) Joslin Diabetes Center, Department of Medicine, Harvard Medical School, Boston, MA

(3) VA Boston Healthcare System, Harvard Medical School, Boston, MA

(4) Spaulding Rehabilitation Hospital, Department of Physical Medicine \& Rehabilitation, Harvard Medical School, Boston, MA

(5) VA Boston Healthcare System, Department of Physical Medicine and Rehabilitation, Harvard Medical School, Boston, MA

(6) Beth Israel Deaconess Medical Center, Harvard Medical School, Boston, MA

\section{Corresponding author:}

Rani Polak, MD, MBA

Institute of Lifestyle Medicine

Department of Physical Medicine \& Rehabilitation, Harvard Medical School 
Spaulding Rehabilitation Hospital, 300, 1st Avenue Boston, MA 02129

Tel: 617-952-6016

Rpolak@partners.org

\begin{abstract}
This case series describes and examines the outcomes of a remote culinary coaching program, aimed at improving nutrition through home cooking. Participants $(n=4)$ improved attitudes about the perceived ease of home cooking $(p<0.01)$ and selfefficacy to perform various culinary skills $(\mathrm{p}=0.02)$; and also in confidence to continue elearning culinary skills and consume healthier food. We believe this program might be a viable response to the need for effective and scalable health related culinary interventions.
\end{abstract}

\title{
Key Words
}

Health coaching, Home cooking, Lifestyle Medicine, Eating behavior, Nutrition, Culinary Medicine

\author{
Abbreviations \\ CHEF - Culinary Healthcare Education Fundamental \\ JDC - Joslin Diabetes Center \\ US - United States
}

\section{INTRODUCTION}


In the United States (US), an important risk factor for morbidity and mortality is unhealthy diet, which is associated with $26 \%$ of deaths and $14 \%$ of disability-adjusted life-years (Murray et al. 2013). Further, healthy nutrition as part of lifestyle intervention was proven to be more effective than medications in preventing chronic diseases such as type 2 diabetes (Knowler et al. 2002). Beneficial associations are suggested between home cooking and consumption of healthy food choices (Monsivais et al. 2014). However, the consumption of pre-prepared food in the US is expanding (Food-Awayfrom-Home 2012), and a survey from 2007-2008 found a decrease in home food preparation (Smith et al. 2013). Barriers include limited time, skills, and cooking confidence (Gatley et al. 2014).

In response, educational interventions that aim to improve culinary skills as both primary and secondary prevention strategies have recently emerged (Reicks et al. 2014). These interventions improve confidence in home cooking and nutrition consumption (Reicks et al. 2014). Recently, we reviewed 10 key worldwide culinary education programs, and found a number of gaps (Polak at al 2016): 1) programs focus on culinary skills rather than proven barriers to home cooking, such as low cooking confidence (Gatley et al. 2014); 2) a majority of programs lack a behavioral change component that addresses the challenges of sustaining home cooking; and 3) most of the programs include hands-on modules in teaching kitchens, which may be ideal, but encounter barriers for scalability including low accessibility and high costs (Reicks et al. 2014) . Therefore, our overarching goal is to develop low cost, scalable health related culinary programs that address common home cooking barriers efficiently and effectively, through culinary skills training combined with behavioral change techniques. 
Health coaching has proven to be effective in promoting nutritional change, through strategies such as participant-directed goal-setting, guided self-discovery, and accountability (Wolever et al. 2013). Recently, health coaching has developed national standards and accreditations (Mittelman. 2015); therefore, health coaching was selected and piloted as the program's behavioral change strategy (Polak et al. 2014). Then, the culinary coaching approach was developed as a form of health coaching to help participants improve nutrition through combining culinary training and coaching as a two pronged approach (Polak et al. 2015). We define culinary coaching as a behavioral intervention that aims to improve nutrition and overall health by facilitating home cooking through an active learning process for participants that combines culinary training with health and wellness coaching competencies. This report describes a remote culinary coaching program and presents our experience with the first four participants at the Joslin Diabetes Center (JDC), Harvard Medical School.

\section{METHODS}

Using the previously described definition of culinary coaching, this novel model was used at the JDC through a program called the Patients Culinary Health Education Fundamental (CHEF) Coaching Program. This innovative program aims to improve participants' nutrition and overall health through remote culinary coaching and combines: 1) live culinary coaching sessions that merge coaching principles with culinary training, and 2) CHEF Coaching resources - several open access recipes, culinary videos and comprehensive culinary classes, that were reviewed and curated specifically to provide 
training for essential home cooking skills such as efficient kitchen workflow, food selection and purchasing.

In May 2015 the Patients CHEF Coaching Program was approved as a service at the JDC. This series presents our experience with and outcomes from the first four participants who responded to our social media marketing from May through June 2015 to participate in the program. Interested patients were considered eligible if they were following any diet for the prevention or management of cardio-metabolic disease. This case series was determined by JDC Committee on Human Studies to not be human subjects research under 45 CFR 46.

The program included 12 weekly one-on-one 30-minute tele-sessions that were delivered by a certified health coach who is also a credentialed chef. At the first session, participants identified their vision regarding home cooking and 3-month goals. During each subsequent meeting, participants reviewed their progress towards reaching the prior week's culinary goals and identified goals for the coming week, using a self-discovery process facilitated by the culinary coach. When patients detected a new culinary skill that is necessary for their progress, he/she was either taught by the culinary coach through discussions or referred to active learning from the CHEF Coaching resources (finding recipes or reviewing videos which address the required skill).

Data presented in this report was collected from the participants' culinary coaching records and incudes: 1) participant's pre and post Cooking with Chef Questionnaire (Condrasky et al. 2011) a self-administrated Likert-scale questionnaire which was validated to evaluate impact of culinary education programs through four cooking attitude items (Cronbach's $\alpha=0.85$ ) and 14 cooking techniques and meal 
preparation self-efficacy items ( $\alpha=0.91),(5$ - strongly agree; 1 - strongly disagree); and, 2) participants goals and accomplishments which were qualitatively documented by the culinary coach through the sessions.

All data analyses were carried out using R (R Core Team. 2013). Descriptive statistics for individual item outcomes are reported as means and standard deviations. Change in individual response items from pre- to post-intervention were assessed using paired t-tests, and summary scores for overall attitude and confidence change were assessed using multivariate mixed effects models.

\section{RESULTS}

The first four participants who completed the program were adult women (age range 30-60). Two of the women were single (participants A, B) and two married (participants C, D) and living in families, each with 2 school-age children. Participant B had type 1 diabetes, celiac disease, and was obese; participant D was overweight; and participants $\mathrm{A}$ and $\mathrm{C}$ were free of metabolic risk factors.

\section{Patients CHEF Coaching process}

Three participants $(75 \%)$ completed the program (A,C,D) as planned after 12 meetings, and one participant (A) ended after the seventh meeting due to life stressors unrelated to the program. All 43 sessions were completed after 30 minutes as planned. All participants defined culinary visions and 3-month culinary goals. Culinary goals were set by participants in all areas which addressed the known home cooking barriers including lack of culinary skills, limited time, and lack of management skills. Examples of goals and accomplishments are presented in Table 1. 
Participants acquired new culinary skills by setting active learning goals using either the CHEF Coaching resources and other remote resources: "I will look for a guacamole recipe and prepare it today" (A); or recipes and video links that were provided by the culinary coach. Further, one patient (B) asked for a hands-on training in a specific skill (cooking chicken breast); thus a 1-hour training was scheduled at the clinic kitchen as a substitute for two remote 30 -minute meetings. This training improved her confidence to continue with self-learning through videos, which she then praised: "It was good! I have the confidence to do it again [to learn a skill from a video]. It was not hard. I would have never known how to do that."

Three patients (A,B,D,) also defined a wellness vision and 3-month wellness goals to address other health behaviors in addition to improving culinary skills (e.g., exercising). These participants started with setting only culinary weekly goals, and added other lifestyle goals during the program's course (between the $4^{\text {th }}-7^{\text {th }}$ meetings). Interestingly, the participant who elected to only define cooking goals (C) nevertheless reported during the sessions that she had been increasing her exercise level. Participant D stopped setting culinary goals after the $9^{\text {th }}$ meeting and instead focused primarily on physical activity, stress reduction, and family relationship goals.

\section{Patients CHEF Coaching outcomes}

Table 2 presents the patients' cooking attitudes and cooking techniques and meal preparation self-efficacy responses. Participants improved attitudes about the perceived difficulty of home cooking from a mean of a 2.88 to $1.94(\mathrm{p}<0.01)$; and self-efficacy to perform various culinary skills for a mean of a 3.44 to $4.11(\mathrm{p}=0.02)$. Further, all of the participants' narratives reflected both these outcomes and supported improved nutritional 
consumption. "I have whole foods in the fridge and I like it!! I am looking at my supermarket cart and it is filled with "real" food compared to others ... all fresh fruits and vegetables and less bags and containers"

\section{DISCUSSION}

This case series presents an evolving innovative remote culinary coaching program and our positive experience from the first four participants. Our initial results were demonstrating that this behavioral intervention might improve participants' attitude about the difficulty to perform home cooking, and confidence to cook. Further, the participants' attitudes consistently improved, and self-efficacy improved in most of the skills that participants had lacked confidence in prior to the program.

Although this is a small case series, the program's positive results align with studies that have demonstrated benefits of health coaching including improvement of participants' health behaviors (Appel et al. 2011); and with studies that have shown that cooking interventions can enhance participants' time spent preparing food, cooking confidence and thus nutrition quality (Reicks et al. 2014).

The program's feasibility is currently being evaluated by training seven individuals who are both chefs and health coaches who are delivering CHEF Coaching programs in their practice, and collecting new data about the training and its implementation with 28 clients. It is our intent to continue evaluating whether the Patient CHEF Coaching will have a significant impact on home cooking, nutrition consumption, health status, and ultimately healthcare costs. 
In comparison to other lifestyle behavior goals (e.g., walking 5 minutes on Sunday afternoon), pursuing culinary goals might require acquisition of a new skills (e.g., making homemade hummus on Friday). Overall, it seems that learning culinary skills from the CHEF Coaching resources were accepted by participants, who also have gained confidence to continue using these resources after completing the program. Our findings correspond with a recent publication that presented the positive impact of culinary videos (Adam et al. 2015). Whether this program can be delivered in a cost efficient manner has yet to be determined; however, a recent summary showed that the costs of remote health related culinary education are lower than hands on education in teaching kitchens (Polak et al. 2016). Thus, remote behavioral interventions might be a sustainable solution to decrease culinary education costs and increase accessibility.

While the main goal of the program participants was to improve their home cooking, all participants addressed other lifestyle behaviors such as exercising. This supports the concept, also shown with fitness coaching, that success in changing one health behavior can generalize to changes in other health behaviors (Wolever et al. 2013). Further, while discussing culinary goals, three participants asked for more nutritional information. Two scheduled a primary care appointment and one did active learning online. This aligns with several culinary programs that combine nutrition with culinary education (Reicks et al. 2014). As we move forward to develop our culinary coaching model through the CHEF Coaching program, we plan to investigate how it can be further integrated with the health care team, primarily with nutrition education and with specific outcome measures regarding improved nutrition that directly affect health outcomes. 


\section{CONCLUSIONS}

This report presents an innovative and novel remote culinary coaching program that improved attitudes and confidence about home cooking. We believe that this program has potential to be a viable response to the need for effective and scalable nutrition education interventions aimed at increasing home cooking.

\section{ACKNOWLEDGEMENTS}

We would like to thank Darlene Trandel, $\mathrm{PhD}$, Health Coach, for her thoughtful input and contribution to this manuscript's formation.

\section{Disclosure}

Rani Polak was supported through his fellowship with educational grants from Maccabi Healthcare Service, Harvard Medical School-Physical Medicine \& Rehabilitation Department, and the Israeli Cancer Association. He also receives author royalties for his book Healthy Diabetes Recipes, Penn publication. Institutions of RP, EMP, DMP, MJA offer the chef coaching as a service.

\section{REFERENCES}

Adam, M., Young-Wolff, K.C., Konar, E., and Winkleby, M. 2015. Massive open online nutrition and cooking course for improved eating behaviors and meal composition. Int. J. Behav. Nutr. Phys. Act.12:143. doi: 10.1186/s 12966-015-0305-2. 
Appel, L.J., Clark, J.M., Yeh, H.C., Wang, N.Y., Coughlin, J.W., Daumit, G., et al. 2011. Comparative effectiveness of weight-loss interventions in clinical practice. $\mathrm{N}$ Engl $\mathrm{J}$ Med. 24;365(21):1959-68. doi: 10.1056/NEJMoa1108660

Condrasky, M., Williams, J., Catalano, P., and Griffin. S.F. 2011. Development of psychosocial scales for evaluating the impact of a culinary nutrition education program on cooking and healthful eating. J. Nutr. Educ. Behav. 43:511-6. doi: 10.1016/j.jneb.2010.09.013

Food-Away-from-Home 2012, US department of agriculture, economic research service. Available at: https://www.ers.usda.gov/topics/food-choices-health/food-consumptiondemand/food-away-from-home.aspx. (Accessed March 6ht 2017)

Gatley, A., Caraher, M., and Lang, T.,A. 2014. Qualitative, cross cultural examination of attitudes and behavior in relation to cooking habits in France and Britain. Appetite,.75:71-81. doi: 10.1016/j.appet.2013.12.014

Knowler, W.C., Barrett-Connor, E., Fowler, S.E., Hamman, R.F., Lachin, J.M., Walker, E.A., et al. 2002. Reduction in the incidence of type 2 diabetes with lifestyle intervention or metformin. N. Engl. J. Med.346(6):393-403.

Mittelman, M. 2015. Health Coaching: An Update on the National Consortium for Credentialing of Health \& Wellness Coaches. Glob. Adv. Health. Med. 4(1):68-75. $\square$ doi: 10.7453 /gahmj.2014.062 
Monsivais, P., Aggarwal, A., and Drewnowski, A. 2014. Time spent on home food preparation and indicators of healthy eating. Am. J. Prev. Med.47:796-802. doi: 10.1016/j.amepre.2014.07.033

Murray, C.J., Atkinson, C., Bhalla. K., Birbeck, G., Burstein, R., Chou, D., et al. 2013. The state of US health, 1990-2010: burden of diseases, injuries, and risk factors. JAMA,.310:591-608. doi: 10.1001/jama.2013.13805

Polak, R., Phillips, E.M., Nordgren, J., La Puma, J., La Barba, J., Cucuzzella, M., et al. 2016. Health related Culinary Education: A Summary of representative emerging programs for health professionals and patients. Glob. Adv. Health. Med.5(1):61-8. doi: 10.7453/gahmj.2015.128

Polak, R., Dill, D., Abrahamson, M.J., Pojednic, R.M., and Phillips, E.M. 2014. Innovation in diabetes care: improving consumption of healthy food through a "Chef Coaching” program: A case report. Glob. Adv. Health. Med.3:42-8. doi: 10.7453/gahmj.2014.059

Polak, R., Sforzo, G.A., Dill, D., Phillips, E.M., and Moore, M. 2015. Credentialed chefs as certified wellness coaches: call for action. Eating. Behav. 19:65-7. doi: 10.1016/j.eatbeh.2015.06.016

R Core Team. 2013. A language and environment for statistical computing. $\mathrm{R}$ 
Foundation for Statistical Computing, Vienna, Austria. http://www.R-project.org/. Accessed at March $10^{\text {th }} 2017$

Reicks, M., Trofholz, A.C., Stang, J.S., and Laska, M.N. 2014. Impact of cooking and home food preparation interventions among adults: outcomes and implications for Future programs. J. Nutr. Educ. Behav. 46(4):259-76. doi: 10.1016/j.jneb.2014.02.001

Smith, P.L., Ng, W.S., and Popkin, M.B. 2013.Trends in US home food preparation and consumption: analysis of national nutrition surveys and time use studies from 1965-1966 to 2007-2008. Nutr. J.12:1-10. doi: 10.1186/1475-2891-12-45

Wennberg, D.E., Marr, A., Lang, L., O'Malley, S., and Bennett, G. 2010. A randomized trial of a telephone care-management strategy. N. Engl. J. Med. 363(13):1245-55. doi: 10.1056/NEJMsa0902321

Wolever, R.Q., Simmons, L.A., Sforzo, G.A., Dill, D., Kaye, M., Bechard, E.M., et al. 2013. A systematic review of the literature on health and wellness coaching: defining a key behavioral intervention in healthcare. Glob. Adv. Health. Med.2:38-57. doi:

10.7453/gahmj.2013.042 
Table 1 - Example of participants' culinary goals domains and accomplishments

\begin{tabular}{|c|c|c|}
\hline $\begin{array}{l}\text { Home cooking } \\
\text { barriers }\end{array}$ & Goal & Accomplishment (stated by participant) \\
\hline $\begin{array}{l}\text { Lack of culinary } \\
\text { skills }\end{array}$ & $\begin{array}{l}\text { Incorporating nuts into the } \\
\text { butternut squash soup on } \\
\text { Thursday }\end{array}$ & $\begin{array}{l}\text { My tool kit has expanded! I am not afraid of using } \\
\text { fish, chicken, and grains [anymore]. }\end{array}$ \\
\hline Limited time & $\begin{array}{l}\text { Making a double batch of } \\
\text { lentils for the tacos tonight } \\
\text { and freeze some for later }\end{array}$ & $\begin{array}{l}\text { I make edamame as a snack for both kids and adults } \\
\text { [at once]. They loved that! The kids share it; I never } \\
\text { thought it would happen! }\end{array}$ \\
\hline $\begin{array}{l}\text { Lack in management } \\
\text { skills }\end{array}$ & $\begin{array}{l}\text { Taking bulgur on the family } \\
\text { vacation and using it for } \\
\text { salads }\end{array}$ & $\begin{array}{l}\text { I have less stuff, but actually more stuff in my } \\
\text { pantry. I take out what I don't need and the things I } \\
\text { need are more accessible. }\end{array}$ \\
\hline
\end{tabular}


Table 2 - Participants cooking attitude, and cooking techniques and meal preparation self-efficacy*

\begin{tabular}{|l|r|c|c|}
\hline & \multicolumn{2}{|c|}{ Mean (SD) } & $p$ \\
\hline & \multicolumn{1}{|c|}{ Pre } & Post & \\
\hline I do not like to cook because it takes too much time. & $2.75(1.23)$ & $2.25(0.96)$ & 0.18 \\
\hline Cooking is frustrating. & $2.50(0.56)$ & $1.75(0.50)$ & 0.06 \\
\hline It is too much work to cook. & $2.75(0.96)$ & $2.00(0.82)$ & 0.22 \\
\hline I find cooking tiring. & $3.50(0.58)$ & $1.75(0.96)$ & $<0.01$ \\
\hline Summary of attitude items & 2.88 & 1.94 & $<0.01$ \\
\hline I fill confident to: & & & \\
\hline Using knife skills in the kitchen & $3.25(1.50)$ & $3.25(1.26)$ & $>0.99$ \\
\hline Using basic cooking techniques & $4.00(1.15)$ & $5.00(0.00)$ & 0.18 \\
\hline Steaming & $4.00(1.15)$ & $4.50(0.58)$ & 0.18 \\
\hline Sautéing & $4.00(1.41)$ & $4.50(0.58)$ & 0.39 \\
\hline Stir-frying & $3.75(1.50)$ & $4.50(0.58)$ & 0.22 \\
\hline Grilling & $2.75(0.96)$ & $3.75(1.26)$ & 0.09 \\
\hline Poaching & $1.50(0.58)$ & $2.75(0.96)$ & 0.08 \\
\hline Baking & $3.50(1.00)$ & $4.25(0.50)$ & 0.06 \\
\hline Roasting & $4.00(0.82)$ & $4.25(0.50)$ & 0.39 \\
\hline Stewing & $2.75(1.71)$ & $3.00(1.15)$ & 0.84 \\
\hline Preparing fresh or frozen green vegetables (eg, broccoli, & $4.00(0.82)$ & $4.50(0.58)$ & 0.50 \\
\hline spinach) & & & \\
\hline Preparing root vegetables (eg, potatoes, beets, sweet potatoes) & $4.00(0.82)$ & $4.50(1.00)$ & 0.18 \\
\hline & & & \\
\hline
\end{tabular}




\begin{tabular}{|l|c|c|c|}
\hline Preparing fruit (eg, peaches, watermelon) & $3.50(1.00)$ & $4.50(0.58)$ & 0.09 \\
\hline Using herbs and spices (eg, basil, thyme, cayenne pepper) & $2.75(0.96)$ & $4.25(0.50)$ & 0.06 \\
\hline Summary of confidence items & 3.41 & 4.11 & 0.02 \\
\hline
\end{tabular}

* 1 - strongly disagree; 5 - strongly agree 